\section{Anorexia nervosa and schizophrenia}

SIR: We report a case of a 54-year-old single woman satisfying all five ICD-10 (WHO, 1992) criteria for anorexia nervosa, occurring together with paranoid schizophrenia, accompanied by religious delusions and the compulsion to fast and pray.

She came from a strongly Conservative Evangelical background and presented with an eight year history, following the break-up of a relationship, believing that God instructed her in the second person to fast. Disobedience produced overwhelming guilt. There were compulsions to shout "Jesus" and to kneel and pray, both producing a feeling of relief. Voices argued about the rightness and wrongness of eating. Fragments of speech and biblical texts (e.g. "comfort all who mourn") were inserted into her mind. She also felt the 'presence' of God controlling her physically.

Her childhood was uneventful and she worked in teaching and secretarial posts. She had become amenorrhoeic at 46 years. A niece had suffered a brief reactive schizophreniform psychosis.

During her admission she would kneel to pray throughout the night which caused both bilateral leg swelling and foot-drop. Under "God's instructions" she induced vomiting, exercised vigorously and took repeated cold showers and she also expressed fear of gaining weight, becoming fat or appearing ugly to others. Affective symptoms were absent. Ten years earlier she weighed $51-54 \mathrm{~kg}$. Weight fell during her admission from 40 to $35.1 \mathrm{~kg}$.

Treatment necessitated detection under Section 3 of the Mental Health Act. She was eventually referred to the Feeding Disorders Unit at the Maudsley Hospital, after failing to respond to various antipsychotics (including trifluoperazine, haloperidol, chlorpromazine and remoxipride), antidepressants, ECT or behavioural programmes. The unit agreed with the tw' $n$ diagnoses.

We believe the patient developed anorexia nervosa secondary to paranoid schizophrenia. Alternatively, schizophreniform symptoms may develop in up to $29 \%$ of anorexic patients (Ferguson \& Damluji, 1988) but these are more commonly 'negative' than 'positive' symptoms, and contrary to the findings of $\mathrm{Hsu}$ et al (1981), we found affective symptoms to be absent. The two conditions could obviously co-exist together by chance.

Bell (1985) described religious fanaticism associated with anorexia in medieval Italy. Our patient pursued weight loss due to disturbed body image and to produce purity of spirit.
Bell (1985) Holy Anorexia. Chicago: University of Chicago Press. FERGUSON \& DAMLUI (1988) Anorexia nervosa and schizophrenia. International Journal of Eating Disorders, 7, 343-352.

Hsu et al (1981) Schizophrenia and anorexia nervosa. Journal of Nervous and Mental Disease, 169, 272-276.

World Hralth Organization (1992) The Tenth Revision of the International Classification of Diseases and Related Health Problems. (ICD-10) Geneva: WHO.

MARTIN ANDREW BRIAN HARRIS

University of Wales College of Medicine

Sully Hospital

S. Glamorgan CF6 2 YA

Mental handicap and the pandemic influenza

SIR: I read with great interest Crow (BJP, May 1994, 164, 588-592) and Selten \& Slaets (BJP, May $1994,164,674-676)$ on influenza and schizophrenia.

I examined the case notes of all mentally handicapped patients admitted to the four hospitals in the Stoke Park Group, Bristol, from the South Western Regional Health Authority, born between 15 August 1957 and 14 August $1958(n=22)$. I also included patients born between 15 August 1955 and 14 August 1957, and between 15 August 1958 and 14 August $1960(n=84)$ and compared the table of O'Callaghan et al (1991).

The number of births between 15 August 1957 and 14 August 1958 was similar to the average number within the same period of the control years. There may be a number of explanations for this: (a) our sample is small and unrepresentative as it only includes hospitalised, most severely mentally handicapped people; (b) mildly mentally handicapped people with superimposed schizophrenia might have been included with schizophrenics in the authors' regional survey; and (c) maternal viral and other infections are sometimes associated with marked congenital abnormalities of the central nervous system, for example anencephaly and other congenital malformations. The children are either stillborn or are mentally handicapped but could have been labelled only according to their associated physical disabilities.

There is a need for further studies of the mental and physical effects of the pandemic A2 influenza of $1957 / 58$ and of 1968/69 (Mattock et al, 1988), excluding other teratogenic agents causing similar damage.

Mattock, C., Marmot, M. \& SterR, G. (1988) Could Parkinson's disease follow intra-uterine influenza?: a speculative hypothesis. Journal of Neurology, Neurosurgery and Psychiatry, 51, 753-756. 